\title{
V2G Strategy for Improvement of Distribution Network Reliability Considering Time Space Network of EVs
}

\author{
Hak-Ju Lee ${ }^{1}$, Byeong-Chan $\mathrm{Oh}^{2}{ }^{2}$, Seok-Woong Kim ${ }^{1}$ and Sung-Yul Kim ${ }^{3, *}$ \\ 1 Smart Power Distribution Laboratory, KEPCO Research Institute, 105 Munji-Ro, Yuseong-Gu, \\ Daejeon 34056, Korea; jureeya@kepco.co.kr (H.-J.L.); sw.kim@kepco.co.kr (S.-W.K.) \\ 2 Department of Electronic and Electrical Engineering, Keimyung University, 1095 Dalgubeol-daero, \\ Daegu 42601, Korea; obchan08@gmail.com \\ 3 Electrical Energy Engineering, Keimyung University, 1095 Dalgubeol-daero, Daegu 42601, Korea \\ * Correspondence: energy@kmu.ac.kr; Tel.: +82-53-580-5251
}

Received: 11 July 2020; Accepted: 21 August 2020; Published: 26 August 2020

\begin{abstract}
Reliability is an important index which determines the power service and quality provided to customers. As the demand increases continuously and the system changes in accordance with the environmental regulation, the reliability assessment in the distribution system becomes crucial. In this paper, we propose methods for improving the reliability of the distribution system using electric vehicles (EVs) in the system. In this paper, EVs are used as power supplying devices, such as a transportable energy storage system (ESS) which supplies power when fault occurs in the system, and by using a time-space network (TSN) in particular, EV capacity in accordance with the load arrival time was calculated. Unlike other existing reliability assessments, we did not use the average load of customers. Instead, by taking into account the load pattern by times, we considered the priority for load supply in accordance with the failure scenarios and failure times. Based on the priority calculated for each time of failure and failure scenario, plans for EV operation to minimize expected customer interruption cost (ECOST), the reliability index in the distribution system, were established. Finally, a case study was performed using the IEEE RBTS (Roy Billinton Test System) 2 Bus and the performance of the model proposed in this paper was verified based on the result.
\end{abstract}

Keywords: reliability; distribution network; electric vehicle; time-space network; ECOST; vehicle to grid

\section{Introduction}

Reliability is an important factor in determining the quality of the service provided to customers in the power sector, and assessment of reliability is an essential element in planning and operating the power system to supply high-quality power to customers stably in response to a continuous increase in power demand [1-3]. In general, reliability of the distribution system is calculated using probabilistic methodologies [4-7]. Reliability of the distribution system is assessed by checking how properly the equipment and system perform the intended functions, and especially, in the case of Korea Electric Power Corporation (KEPCO), they have the target of achieving 6.64 in the System Average Interruption Duration Index (SAIDI) which is one of the distribution system reliability indices in 2020. For such reasons, studies on improving the reliability in various ways have been carried out across nations, and globally in recent years, using the demand responses and line connections, as well as utilizing distributed energy resources (DERs), energy storage systems (ESSs) and introducing renewable energies [8-12]. 
In [13], considering the cost, the authors suggested ways of improving the reliability using synthetic feeders which can be applied to various distribution systems more promptly, and in $[14,15]$, the authors suggested methods of improving the reliability of distribution systems and microgrids by introducing and utilizing renewable energy. Further, methods of improving the reliability using demand response resources and renewable energies, considering the situations where the failure restoration for all customers may be impossible, are suggested in [16,17].

However, there are uncertainties due to the intermittent output of renewable energy and there may be situations where power cannot be supplied when needed. The authors of [18] showed the case where they used an ESS to make up for the uncertainty in the output of renewable energy, and they studied the ways of improving the reliability of the system by calculating the optimal capacity of the ESS using the mixed-integer linear programing method. In [19], the authors suggested a method of improving the reliability by connecting to existing distributed generations (DGs), considering the cost.

The theories mentioned above are methods taking into account the viewpoints of system planning, and there may be cases where the supply of power is not flexible depending on areas when failures occur during operation. In the previous studies, the average load in the system is used without considering the failure occurrence time for the reliability evaluation, and the optimal location of DERs are selected through MCS or a stochastic approach [20]. This does not provide flexibility for different failure scenarios because it selects one optimal location to improve the system reliability.

To solve such problems, various studies on ways of improving the reliability are currently in progress and there have been studies on stabilizing microgrids (MGs) and systems and assessing the reliability utilizing vehicle to grid (V2G) in recent years [21,22]. Electric vehicles (EVs) can be considered as portable ESSs, and [23-26] show studies on reliability assessment with the existing EVs, which use procedures for failure restoration with V2G, EV charge/discharge scheduling and system reconfiguration.

Here, we need to provide procedures for failure restoration with V2G, as a way to improve reliability, as detailed as possible from the viewpoint of operation. In particular, unlike the existing reliability improvement method, EVs provide a very flexible response to various fault scenarios because they can move directly to failure points, taking into account the hourly load priority, and providing power. In this paper, an EV is used as the same concept as a transportable ESS to suggest ways to improve the system reliability in this article. Assessment of system reliability with V2G scheduling is carried out, and for V2G scheduling according to fault scenarios, load priority is selected through load analysis and the optimal hourly V2G linkage method is presented.

In this paper, we suggest ways to improve the system reliability in which optimal system connection points for fault sections are calculated with V2G technology to minimize the expected customer interruption cost (ECOST). By analyzing the initial state of charge (SOC) and available EVs for V2G, optimal EV capacity and number of units are calculated for fault scenarios and procedures for system reliability assessment are analyzed by times to provide ways to improve the reliability. In addition, we propose the time-space network (TSN) modeling method using EVs so that it can be easily applied to various systems and verify the system reliability improvement method proposed in this paper in a more complex environment than the previous study [26].

The main content and configuration of this paper are shown as below.

- From an operating point of view, the optimal strategy of V2G for each failure scenario is provided to improve the reliability of the distribution network;

- We select the time-based load priority according to the failure scenario and the optimal EV-network linkage location to minimize ECOST;

- The distribution network reliability is evaluated by the optimal location of EVs and V2G scheduling according to the failure scenario.

This paper is configured as follows: an overview of the problem definitions and ways to solve them are introduced in Section 2. Ways to calculate indices for assessing the system reliability are 
described in Section 3 and EV charge/discharge scenarios for fault scenarios and ways of improving the system reliability utilizing V2G are described in Section 4. Lastly, a case study and the conclusion are in Sections 5 and 6, respectively.

\section{Problem Definition and Proposed Solution}

In this section, the overall description of ways of utilizing V2G for failure restoration and processes of improving the reliability are described. If line failures occur in the system, corresponding loads connected to the fault line are isolated from the main grid by the operating duties of protection devices like breakers and reclosers, and the control system, and thus power supply to corresponding areas becomes impossible. Protection devices remain opened until the failures are restored. Details of the operations of protection devices and control technology can be found in [27].

Supplying power through DG connection is the typical way which is taken in the stage of power system planning for improving the grid reliability $[28,29]$. If there are DGs in the islanded area, power can be supplied to the area during the failure, however, if the DG is connected to other loads, the loads in the failed area cannot receive power during the failure.

In this paper, to make up for such problems and to provide ways of improving the reliability from the viewpoint of system operation, we propose ways of improving the failure restoration with V2G scheduling. It is assumed that the loads in the failed area receive power through V2G technology utilizing the EVs existing in each area during the failure. Connection points between EVs and the grid are determined in the way that the ECOSTS of the loads existing in the islanded area are analyzed for corresponding scenarios and times, and the point with maximum ECOST is selected. Details regarding equations for calculating reliability indices like ECOST and SAIDI, and the way of calculating the reliability are described in Section 3.

After the optimal EV connection point is determined by comparison of reliability indices, the number of available EVs at that point is determined and more accurate power available for the supply is analyzed considering the time to be taken for the EVs to arrive at the point. Thus, V2G scheduling for supplying the power to the failed area is modeled taking into account the estimated EV capacity, number of EVs and time to be taken for EVs to arrive at the connection point. Details regarding the EV capacity, number of EVs needed, time to be taken and network modeling are described in Section 4.

Finally, the assessment of the reliability of the whole system is carried out based on the operation of V2G. Figure 1 shows the flowchart of the proposed method for the assessment.

In this paper, the system reliability assessment with the application of the proposed method is carried out along with the reliability assessment of the system connected with the existing DGs, and validity is verified by comparison of two indices calculated from the two methods. 


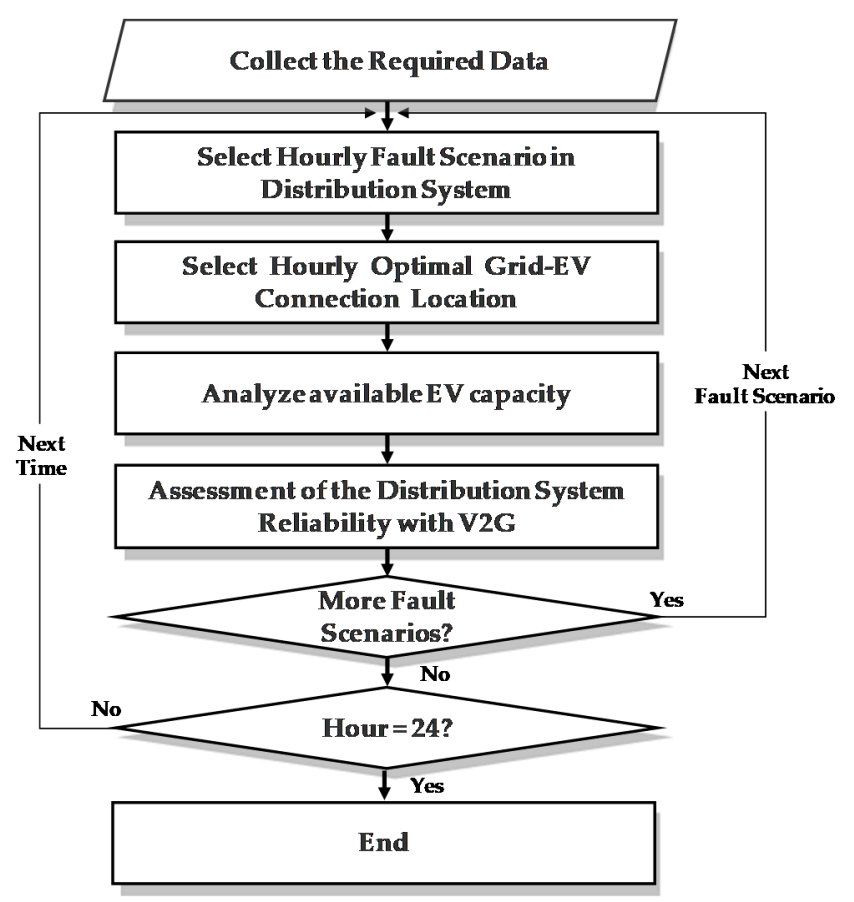

Figure 1. Flowchart of the proposed method for the system reliability assessment.

\section{Reliability Assessment Indices}

\subsection{Radial Distribution System}

In ordinary power systems, the status of the distribution equipment near the customers affects the supply of power to customers much more than those of generation and transmission systems. Therefore, we need to analyze the reliability of the distribution system. Corresponding reliability indices are defined in [30]. To calculate the system reliability indices, we need to analyze the status of customers affected by the failures of lines and cables as well as protection devices such as breakers, fuses and reclosers in the distribution system. When doing so, calculation of the reliability indices is possible, taking only into account the components affecting the each load point rather than considering all equipment. In this article, the distribution system reliability assessment is carried out with the use of a radial system.

\subsection{Reliability Indices Calculation in Distribution System}

As shown in [30], the indices needed for the reliability assessment are calculated with the mean time to failure (MTTF) and mean time to repair (MTTR) of the components connected to the load points. In the case of an ordinary radial system, average failure rate $\left(\lambda_{i}\right)$, average outage time $\left(r_{i}\right)$ and yearly average outage time $\left(U_{i}\right)$ can be calculated using Equations (1)-(3).

$$
\begin{gathered}
\lambda_{i}=\sum_{j=1}^{N_{j}} \lambda_{j} \\
r_{i}=\frac{U_{i}}{\lambda_{i}}=\left(\sum_{j=1}^{N_{j}} \lambda_{j} r_{j}\right) / \sum_{j=1}^{N_{j}} \lambda_{j} \\
U_{i}=\sum_{j=1}^{N_{j}} \lambda_{j} r_{j}
\end{gathered}
$$


where $N_{j}$ means the number of components affecting the load point $i$, and $\lambda_{j}$ and $r_{j}$ mean the average failure rate and average outage time of the component $j$, respectively.

The system average interruption frequency index (SIAFI), system average interruption duration index (SAIDI) and energy not supplied by the system (ENS) are used as representative indices for the system assessment and expected customer interruption cost (ECOST) is also used to calculate the connection points of the EV system. The distribution system reliability indices can be described by Equations (4)-(7) as below.

$$
\begin{gathered}
\text { SAIFI }=\frac{\text { Total Number of Customers Interruptions }}{\text { Total Number of Customers Served }}=\frac{\sum_{i=1}^{N_{L}} N_{i} \lambda_{i}}{\sum_{i=1}^{N_{L}} N_{i}} \\
\text { SAIDI }=\frac{\text { Sum of Customer Interruptions Durations }}{\text { Total Number of Customers }}=\frac{\sum_{i=1}^{N_{L}} N_{i} U_{i}}{\sum_{i=1}^{N_{L}} N_{i}} \\
\text { ENS }=\text { Energy Not Supplied by the system }=\sum_{i=1}^{N_{L}} P_{L, i} U_{i} \\
\text { ECOST }=\text { Expected Customer Interruption Cost }=\sum_{i=1}^{N_{L}} P_{L, i} U_{i} C_{i}
\end{gathered}
$$

where $N_{L}$ means the number of load points in the system, $N_{L}$ means the number of customers experiencing the failure when failure occurs at the load point $i, P_{L, i}$ means the power consumed at $i$, and $C_{i}$ means the outage cost at $i$.

\section{Operational Reliability Improvement using V2G}

In Section 4, system fault scenarios are organized and optimized by modeling which minimizes the ECOST for each fault scenario and algorithms for solving problems are described. Details of the optimized modeling and solving problems are described in Sections 4.2 and 4.3, and here in Section 4.1, methods of organizing fault scenarios for system reliability assessment are described.

\subsection{System Fault Scenario Construction}

System reliability assessment shall be carried out targeting the minimization of ECOST in consideration of economic losses during the failure from the viewpoint of system operation. Thus, in this article, we carry out the system reliability assessment by taking into account the worst situations, and it is assumed that the following fault scenarios occur in the distribution system.

- $\quad \mathrm{N}-1$ contingency in the system is taken into account, and the 3-phase short circuit fault which was influenced by the fault the most is assumed to have occurred;

- The fault occurs at the head of the feeder leading to load and it makes all loads impossible to be supplied from the power grid;

- After the fault occurred, the fault area is islanded by the operation of the protection devices such as breakers, reclosers and fuses;

- ECOST occurs in accordance with the power consumption and fault duration in the islanded areas until the fault is cleared. 


\subsection{Time-Space Network modeling}

To calculate the power supply more accurately, the time for the EV to arrive at the node must be taken into account. Especially, the arrival time of the EV at the node and the available capacity shall be figured out within a given time, and thus we need to configure a time-space network, and so to do the V2G scheduling dynamically, we model the arrival time of the EV for each node using a TSN (time-space network) in this article.

A TSN is mainly used in modeling for allocation scheduling or railway conflict resolution, and it can be explained in equations using mixed-integer linear programming, and thus a time-space network can be modeled simply and effectively $[24,31]$.

A TSN model $G$ consists of a nodes and arcs set $\left(\Omega_{n}, \Omega_{a}\right)$. Here, the arc is divided into a driving $\operatorname{arc} a_{n, i}^{d}$ and a parking arc $a_{i}^{p}$. Further, if any EV route $r$ satisfies $r=a_{n, i}^{d}$ or $a_{i}^{p}$, the binary variable $f_{e}(r)$ value is 1 . The concept of TSN is illustrated in the simple example below.

Figure 2 shows the arrival time of the EV for each load in an arbitrary system by modeling with a TSN. Arrival time is on the vertical axis and node scale is on the horizontal axis. The TSN consists of nodes, marked in black, and arcs to represent driving and parking. Arcs are divided into EV driving arc and EV parking arc. If the EV arrival time between each node is equal to the number on the left side of Figure 2, each arc can be represented as shown on the right side of Figure 2. Here, if the allowable EV arrival time $\zeta_{a}$ is selected within 2 time intervals, the driving arc departing from LP1 is excluded from the EV available capacity calculation because the arrival time is longer than $\zeta_{a}$. Therefore, it is possible to model the actual EV driving arc (marked in red) and the EV parking arc (marked in blue) in LP2, thereby calculating the available EV capacity in LP2.
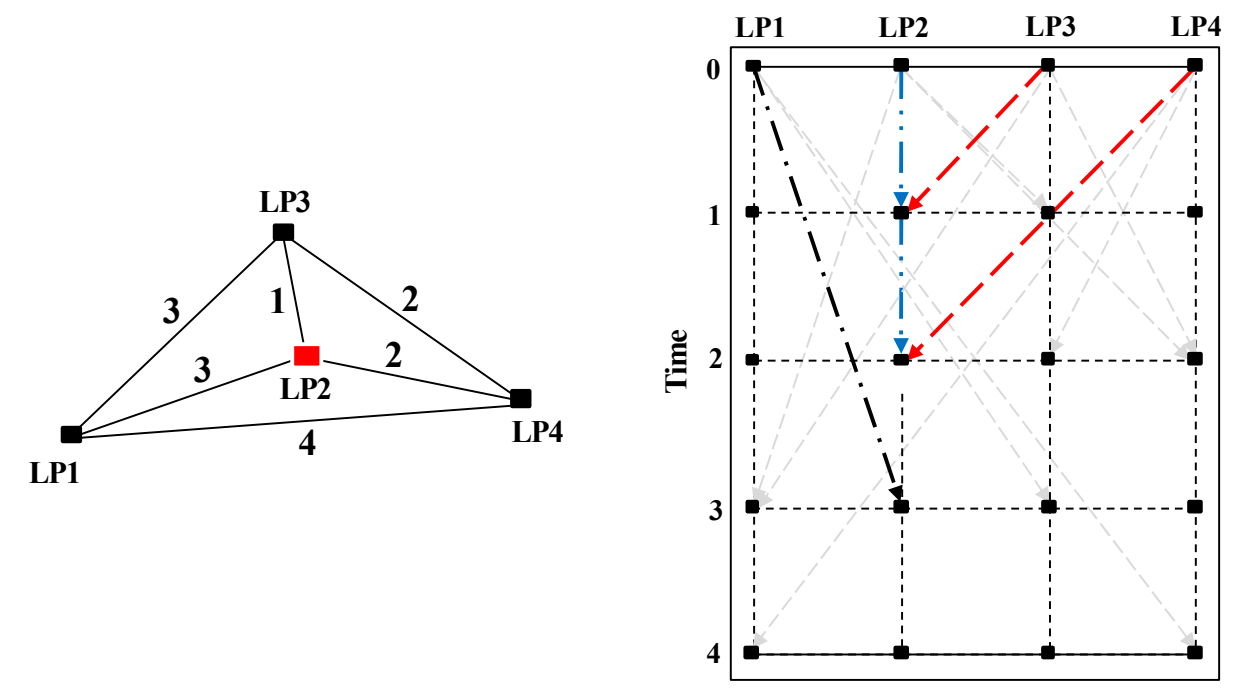

\begin{tabular}{|l} 
Node \\
Node : V2G point $\quad-\cdots, \cdots-\cdots \rightarrow$ EV Parking arc \\
$\square$
\end{tabular}

Figure 2. Example of time-space network modeling.

\subsubsection{Objective Function}

Using the TSN model described above, the objective function for calculating the available capacity of the EV at the node $i$, taking into account the allowable arrival time $t=\zeta_{a}$, is expressed by the equation shown below.

$$
{ }_{o b j} \cdot C_{i}^{t}=\max \sum_{e \in \Omega_{e}} \sum_{r \in \Omega_{a}} N_{e} C_{e} f_{e}(r), \quad \forall t \in T_{f}
$$


where $C_{i}^{t}$ means the available EV capacity at the node $i$, considering the allowable arrival time $\zeta_{a}, N_{e}$ means the number of EVs at each $e$, and $C_{e}$ means the capacity of the EV at each $e$.

4.2.2. Operation Constraints of TSN

$$
\begin{gathered}
\sum_{e \in \Omega_{e}} \sum_{r \in \Omega_{a}} N_{e} f_{e}(r) \leq N_{i}^{l m}, \forall i \in \Omega_{n} \\
f_{e}(r)=\left\{\begin{array}{ll}
1 & \text { if } p=a_{n, i}^{d} \text { or } a_{i}^{p} \\
0 & \text { otherwise }
\end{array}, \forall r, a_{n, i^{d}}^{d}, a_{i}^{p} \in \Omega_{a}, e \in \Omega_{e}\right. \\
a_{n, i^{\prime}}^{d} \quad a_{i}^{p}=\left\{\begin{array}{ll}
1 & \text { if } \zeta_{n, i^{\prime}}^{d} \zeta_{i}^{p} \leq \zeta_{e} \\
0 & \text { otherwise }
\end{array}, \forall a_{n, i^{\prime}}^{d}, a_{i}^{p} \in \Omega_{a}, e \in \Omega_{e}\right.
\end{gathered}
$$

The number of EVs arriving at node $i$ must meet constraint (9) because the number of EVs arriving at node $i$ must not exceed the EV acceptance number in $i$. Constraint (10) ensures whether the route $r$ is used in $e$. Here, route $r$ is used if $\operatorname{arc} a_{n, i}^{d}$ or $a_{i}^{p}$ satisfies constraint (11). Constraint (11) describes a constraint for considering only the arcs in which $e$ is driven or parked within $\zeta_{a}$.

\subsubsection{Constraints of EV Operation}

To analyze SOC for the discharge of EV more accurately, the SOC of EV in accordance with the distance shall be analyzed as well as TSN modeling [32]. In the distribution system, SOC equations according to the distance can be calculated as shown below.

$$
\begin{gathered}
S O C_{e, i}^{t}=S O C_{e}^{i n i}-\frac{D_{e}}{\eta_{e} C_{e}}, \quad \forall t \in T_{f}, e \in \Omega_{e}, i \in \Omega_{n} \\
S O C_{e, i}^{t+1}=S O C_{e, i}^{t}-\frac{P_{e, i}^{t} \Delta t}{\eta_{e, d c h} C_{e, i}^{t}}, \quad \forall t \in T_{f}, e \in \Omega_{e}, i \in \Omega_{n} \\
\operatorname{SOC}_{e}^{\min } \leq \operatorname{SOC}_{e, i}^{t} \leq S O C_{e}^{\max }, \quad \forall t \in T_{f}, e \in \Omega_{e}
\end{gathered}
$$

where $S O C_{e, i}^{t}$ means $S O C$ in accordance with the distance when arrived at $t, D_{e}$ means the EV distance $(\mathrm{km})$ of $e, \eta_{e v}$ means the EV efficiency $(\mathrm{km} / \mathrm{kWh})$ of $e, S O C_{e v, d}^{t+1}$ means the SOC in accordance with the EV discharge at $t+1, \eta_{e, d c h}$ means the discharge efficiency of $e, S O C_{e}^{i n i}$ denotes initial $S O C$ in $e$, and $S O C_{e}^{\text {min }}$ and $S O C_{e}^{\max }$ denote the minimum and maximum SOC in $e$.

Constraint (12) represents the $S O C$ considering the mileage $D_{e}$ of $e$. In addition, the power loss occurs during the process of discharging, which can be described by constraint (13). Constraint (14) limits the minimum and maximum SOC of $e$.

\subsubsection{Operation Constraints of Distribution System}

In order to supply power through the V2G for fault recovery, the following constrains must be met:

$$
\begin{gathered}
\sum_{i \in \Omega_{n}} P_{G, i}^{t}-\sum_{i \in \Omega_{n}} P_{L, i}^{t}+\sum_{j \in k_{f}} P_{e, j}^{t}=0, \quad \forall i \in \Omega_{n}, \quad t \in T_{f} \\
P_{i}^{\min } \leq P_{G, i}^{t} \leq P_{i}^{\max }, \quad \forall i \in \Omega_{n}, \quad t \in T_{f} \\
V_{i}^{\min } \leq V_{i}^{t} \leq V_{i}^{\max }, \quad \forall i \in \Omega_{n}, \quad t \in T_{f} \\
f_{l}^{\min } \leq f_{l}^{t} \leq f_{l}^{\max }, \quad \forall t \in T_{f}, \quad l \in \Omega_{l} \\
0 \leq P_{e, i}^{t} \leq P_{L, i^{\prime}}^{t}, \forall i \in \Omega_{n}, \quad t \in T_{f}
\end{gathered}
$$


where $P_{G, i}^{t}$ means the power received from the grid at $i$ at time $t, P_{i}^{\min }$ and $P_{i}^{\max }$ mean the minimum and maximum allowable capacity supplied to node $i, V_{i}^{\min }$ and $V_{i}^{\max }$ mean the minimum and maximum voltage in $i$, and $f_{i}^{\min }, f_{i}^{\max }$ mean the minimum and maximum allowable current in $i$. Constraint (15) is the equation for power balance for each islanded area $i$. Constraints (16)-(18) are equations for allowable transmission capacity, voltage deviation and allowable line current, respectively. Constraint (19) gives the range of the power supply through the EV.

\subsection{Opitmal Location and Sizing of Electircal Vehicle}

Optimization Model

An optimization model is used when supplying power to the failed area using V2G scheduling in the case of failure in the system operation, for determining the connection point of the EV where the $E C O S T$ is minimized. The function for determining the optimal connection point for the failure time and failed area is as shown in equation (20).

$$
i_{o p t, f}^{t}=\operatorname{Max} \sum_{t \in T_{f}} E \operatorname{COST}_{i}^{t} l_{\forall i \in k_{f}}
$$

where $i_{o p t, f}^{t}$ means the optimal EV connection point, and ECOST ${ }_{i}^{t}$ means the ECOST at the islanded area $k_{f}$ for the failure time and the failed area. Therefore, EVs are connected for each $k_{f}$ with $i_{\text {opt, }}^{t}$ for the loads with the highest outage cost to be supplied power first. The flowchart for the optimization algorithm for connecting to the system using the proposed V2G is shown in Figure 3. The priority of supplying among loads is determined by calculating the point where the ECOST described above is minimized, and the result of the study which proposed the reliability is verified through comparison between SAIDI, ECOST and ENS.

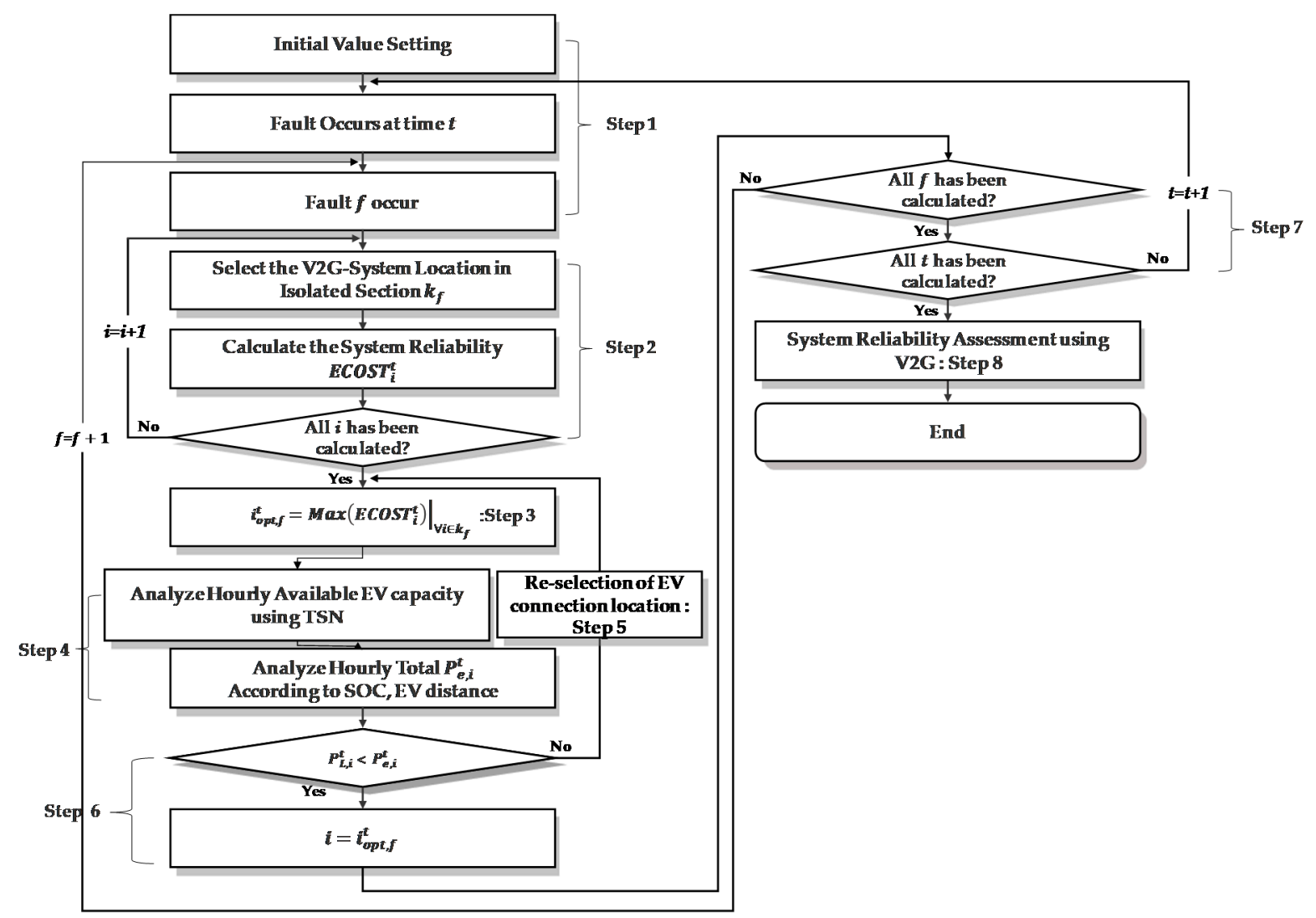

Figure 3. Flowchart of the optimization algorithm. 
The detailed process of the optimization algorithm is performed in the following steps:

- Step 1: Data for system reliability assessment are collected, and the initial values for failure time $t$, fault scenario $f$ and islanded area $k_{f}$ are set. It is assumed that the fault scenario mentioned in Section 4.1 has occurred;

- $\quad$ Step 2: For all $i$ in the islanded area $k_{f}$, analyze ECOST $i_{i}^{t}$,

- Step 3: Select the EV connection point $i_{\text {opt }, f}^{t}$ through the calculated ECOST ${ }_{i}^{t} \cdot i_{\text {opt }, f}^{t}$ means the point at which the ECOST ${ }_{i}^{t}$ analyzed in Step 2 is the maximum;

- Step 4: $P_{e, i}^{t}$ is calculated considering the arrival time of the EV at $i_{o p t, f}^{i}$, using the TSN model;

- Step 5: Here, the connection point $i_{\text {opt, }}^{i}$ which was calculated in Step 3 can be changed according to the value of $P_{e, i}^{t}$ calculated in Step 4 . In the case where the demand at $i=i_{o p t, f}^{t}$ exceeds the supply provided by EVs, demand cannot be met despite the use of V2G and the failed state remains. Thus, the connection point is re-determined such that $E C O S T_{i}^{t}$ is minimized at all $i$ where the power demand is less than or equal to $P_{e, i^{t}}^{t}$

- Step 6: EVs are connected to $i_{\text {opt,f }}^{t}$ and proceed with V2G scheduling. If there are EVs available even after the demand at $i_{\text {opt, f }}^{t}$, the power is supplied to loads with high ECOST and the optimization V2G scheduling for times is carried out;

- Step 7: Through Step 2-Step 6, $i_{o p t, f}^{t}$ and $P_{e, i}^{t}$ are determined for all $t, f$ and V2G scheduling is carried out;

- Step 8: Finally, distribution network reliability is evaluated.

For the clear explanation, a simple example of the optimization algorithm process is given below using the sample system as shown in Figure 4.

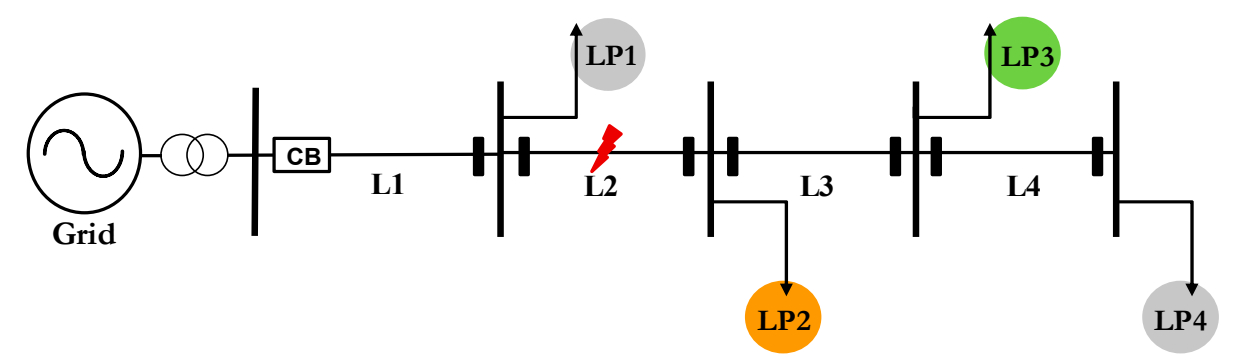

Figure 4. An example of a fault scenario in the test feeder.

In case a fault occurs at L2, protection devices work, and the system is divided such that LP2-LP4 are islanded and cannot be supplied while LP1 is supplied. LP2-LP4 in the islanded area are supplied using $\mathrm{V} 2 \mathrm{G}$ in the way that loads with higher ECOST have priority in receiving power. Here, the EV supply power is calculated considering the EV arrival time and SOC as described in Sections 4.2.2 and 4.2.3.

Figure 5 shows the type and information of each load, power demand (the upper three graphs) and the available power supply by times (the lower three graphs). In case a failure occurs at $t=1$, ECOST occurs in the sequence of LP2-LP3-LP4 with USD 12, USD 9 and USD 4, and the V2G connection point is LP2 with the highest ECOST. However, because the power available in time band $t=1$ is $2[\mathrm{kWh}]$, it is impossible to meet the demand of LP2, and LP4, of which ECOST is highest among the loads with demand that can be met by the supply available in the corresponding time band, becomes the optimal connection point. 

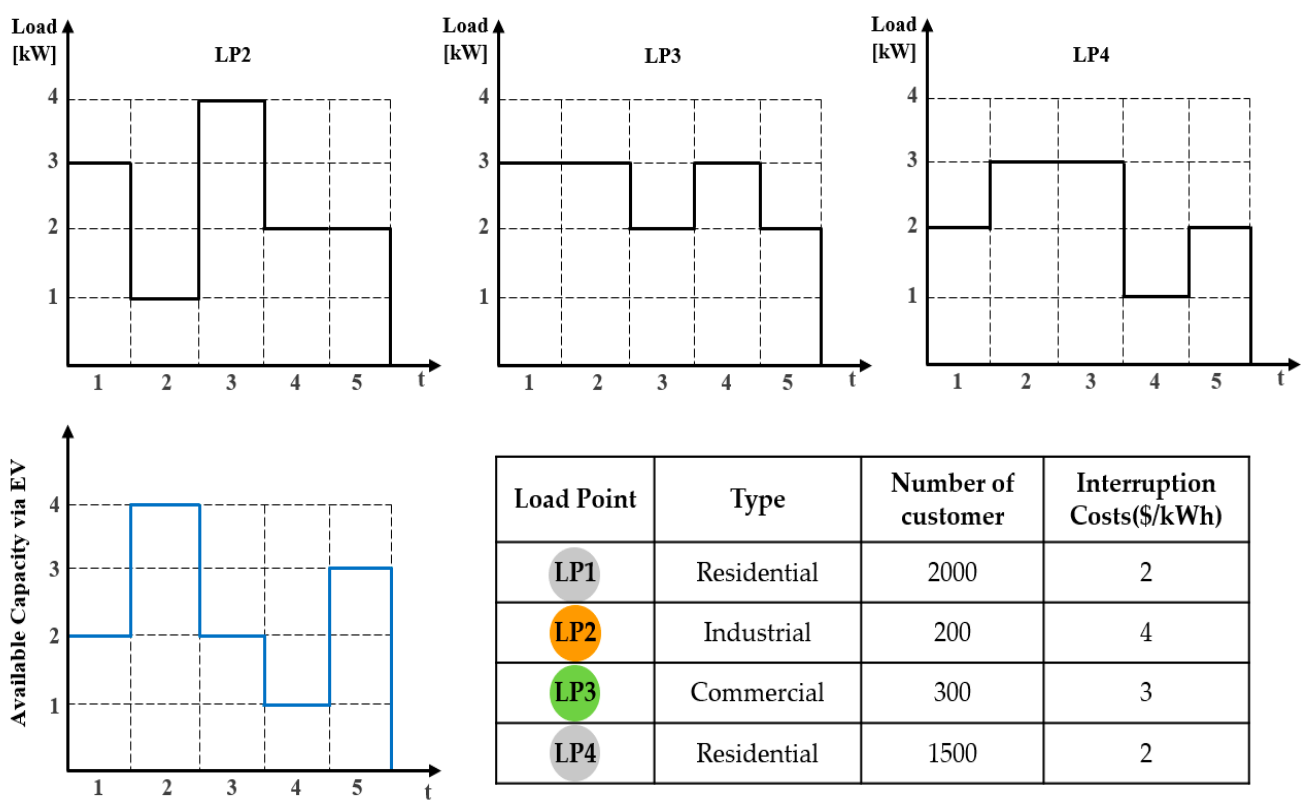

\begin{tabular}{|c|c|c|c|}
\hline Load Point & Type & $\begin{array}{c}\text { Number of } \\
\text { customer }\end{array}$ & $\begin{array}{c}\text { Interruption } \\
\text { Costs } \mathbf{(} / \mathbf{k W h})\end{array}$ \\
\hline LP1 & Residential & 2000 & 2 \\
\hline LP2 & Industrial & 200 & 4 \\
\hline LP3 & Commercial & 300 & 3 \\
\hline LP4 & Residential & 1500 & 2 \\
\hline
\end{tabular}

Figure 5. Information of the example system.

Likewise, in the case of failures at $t=2$, LP3, of which ECOST is highest among the loads that can be met by the supply available in corresponding time band, becomes the connection point and receives power from EVs. In this case, there is $1[\mathrm{kWh}]$ of power available after supplying LP3. To minimize the system ECOST and degree of failure, the remaining power after supplying LP3 is supplied to LP2 which is the next connection point.

\section{Simulation and Case Study}

\section{Test System Data}

The Roy Billinton Test System (RBTS) is a test system to evaluate the reliability of power systems and it can be used to examine a newly developed method [33]. In terms of distribution network reliability, the configuration of the power system for applying the proposed algorithm and reliability data were configured with the use of modified RBTS 2 Bus as shown in Figure 6. It was assumed that fuses and breakers worked correctly, and they were not taken into account in the calculation of reliability. Automated contingencies were composed on lines L1, L12 and L26, and the types of loads existing in the system were classified as residential, industrial and commercial. Load patterns depending on the type are shown in Figure 7, and the data on power consumption and outage cost for types can be found in Statistics Korea and [34]. In this article, a case study was conducted using Electrical Transient Analyzer Program (ETAP) and Matlab 2019(b), which are widely used for power system reliability analysis. 


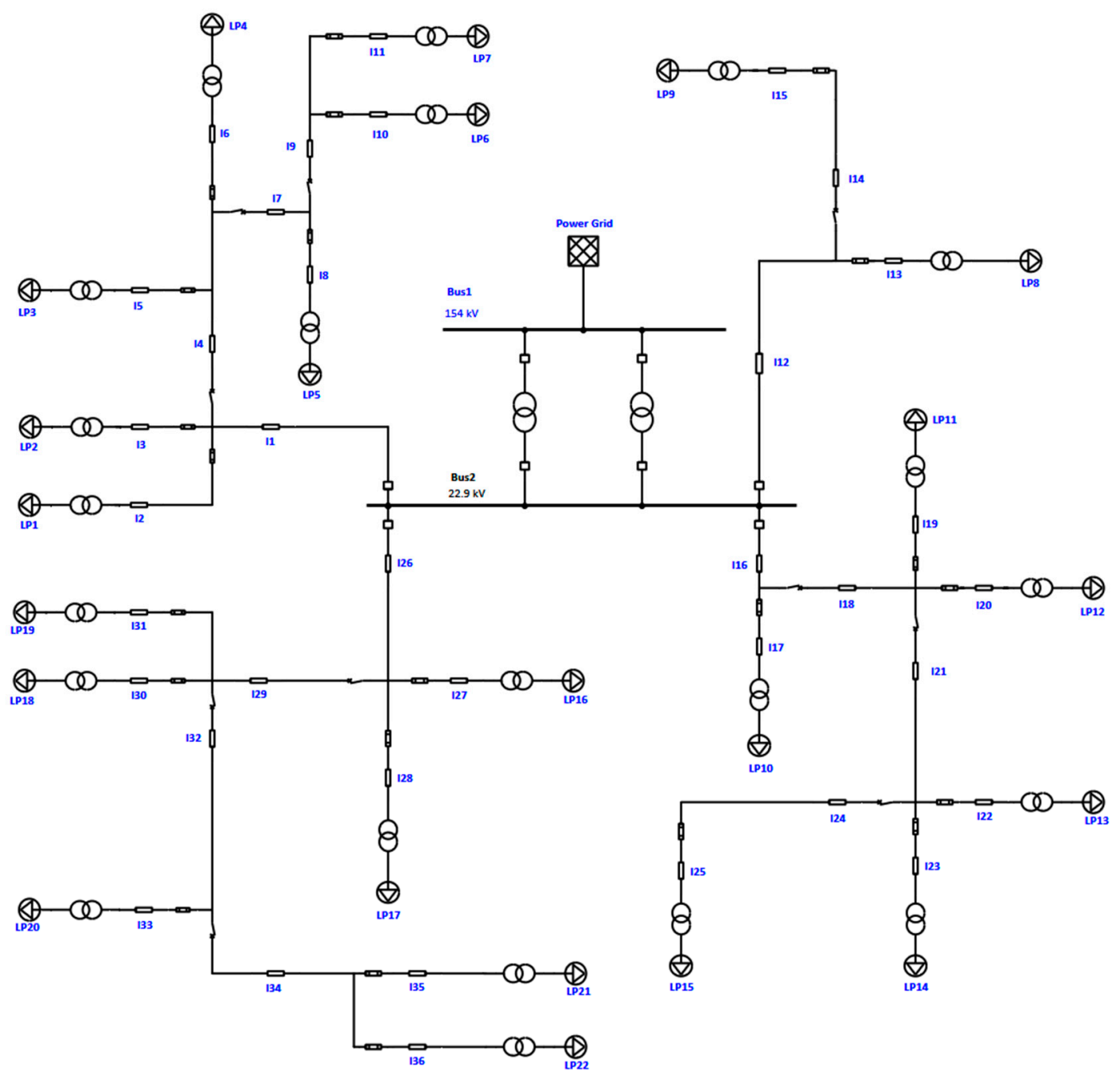

Figure 6. The modified RBTS Bus 2.

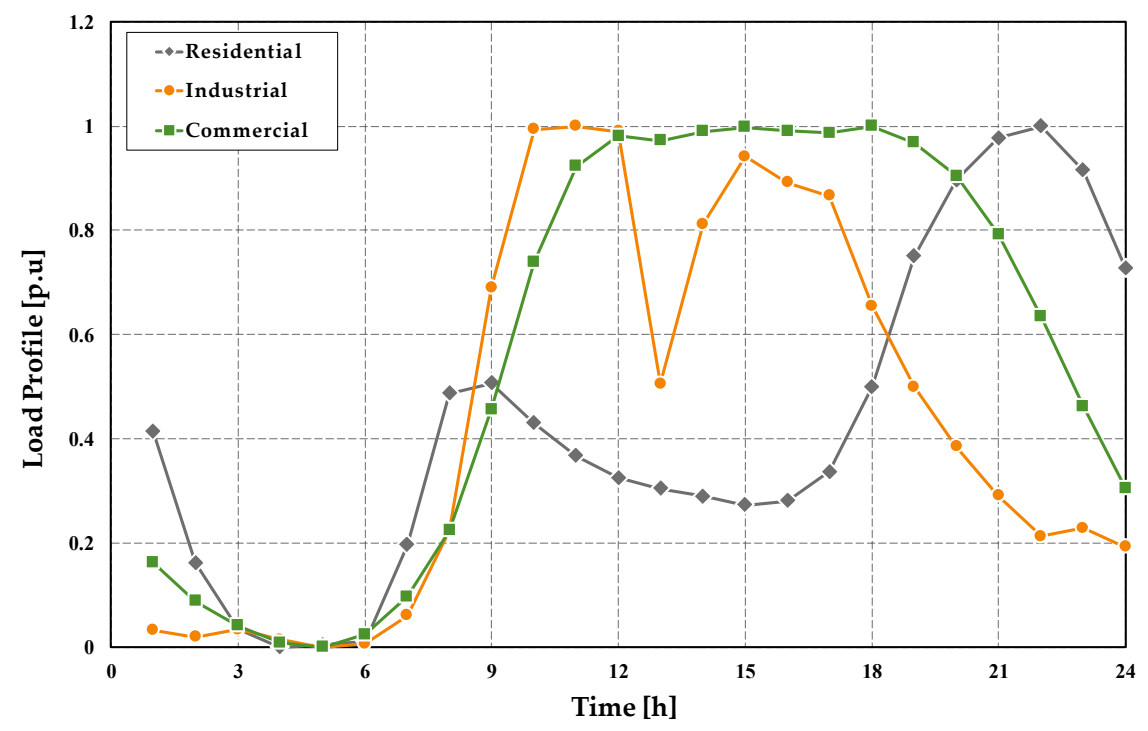

Figure 7. Load profile by customer type.

To calculate the available EV capacity using a TSN, the number of EVs for each load was set based on the number of EVs supposed to be supplied to the whole population in Jeju by 2030. The data 
needed for analyzing the system reliability are shown in Table 1 . Table 2 shows the EV parameters for V2G scheduling.

Table 1. Load information data in modified RBTS 2 Bus.

\begin{tabular}{ccccc}
\hline Type & Load Point & $\begin{array}{c}\text { Number of } \\
\text { Customers }\end{array}$ & $\begin{array}{c}\text { Number of } \\
\text { EVs }\end{array}$ & $\begin{array}{c}\text { ECOST } \\
\text { [USD/kWh] }\end{array}$ \\
\hline \multirow{3}{*}{ Residential } & $7,12,14,18$ & 300 & 22 & \\
& $5,8,17$ & 400 & 29 & 5.63 \\
& 3,21 & 600 & 43 & \\
Industrial & 6,9 & 3 & 3 & 158.63 \\
& 16 & 4 & 4 & \\
\hline \multirow{2}{*}{ Commercial } & 13,22 & 5 & 5 & 18.57 \\
& 1,10 & 10 & 5 & \\
\hline
\end{tabular}

Table 2. Electric vehicle (EV) parameters for V2G scheduling.

\begin{tabular}{cc}
\hline Parameter & Value \\
\hline Discharging Power & $30[\mathrm{kWh} / \mathrm{h}]$ \\
EV Capacity $\left(C_{e}\right)$ & $100[\mathrm{kWh}]$ \\
Initial $S O C\left(S O C_{e}^{\text {ini }}\right)$ & 0.7 \\
$\operatorname{SOC}_{e}^{\max } / S_{\mathcal{e}} C_{e}^{\min }$ & $0.9 / 0.1$ \\
Discharging Efficiency $\left(\eta_{e, d c h}\right)$ & $0.95[\%]$ \\
EV Efficiency $\left(\eta_{e}\right)$ & $7[\mathrm{~km} / \mathrm{kWh}]$ \\
\hline
\end{tabular}

Arc modeling is implemented in matrix form and features a symmetric matrix. The arrival time of the arc is assumed to be 5 minutes per $\mathrm{km}$, as shown in Figure 8. In Figure 9, each row and column indicate the start node and the arrival node, and values in the table are $\zeta_{n, i}^{d}$. Here, the units are marked in minutes. It is assumed that parking arc $\zeta_{i}^{p}$ can be inserted immediately after fault occurs.

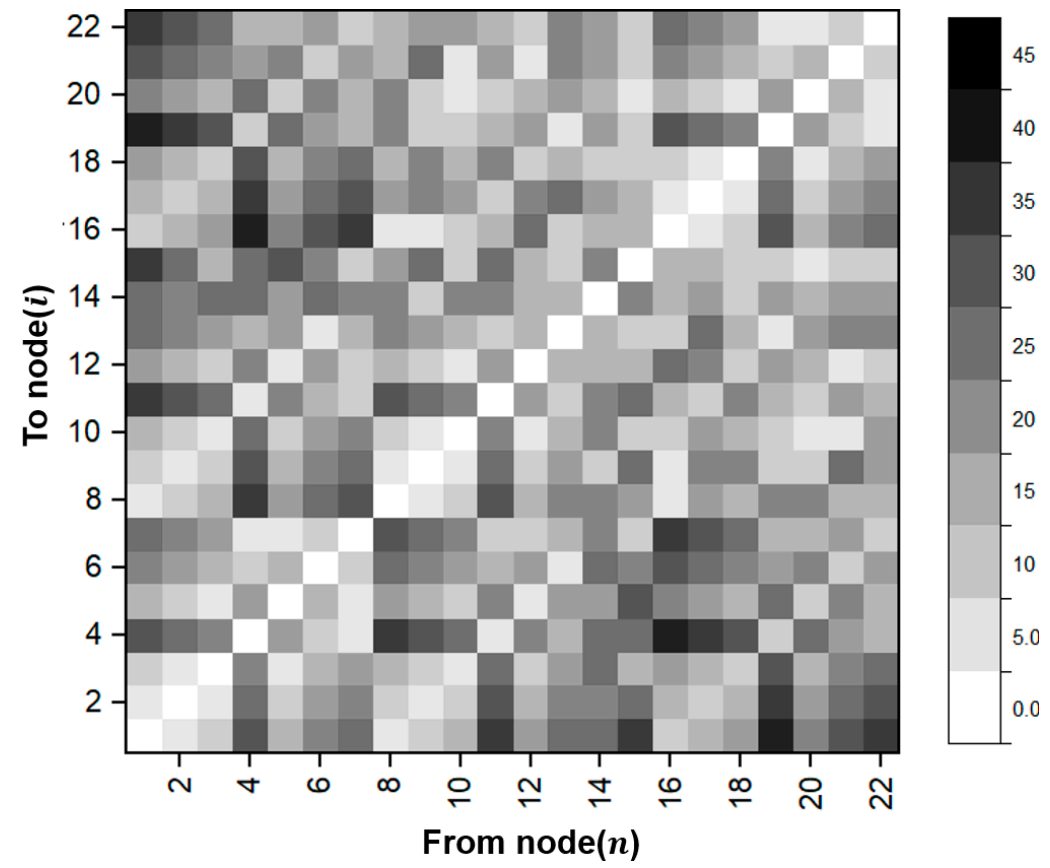

Figure 8. Arc modeling in RBTS 2 Bus. 


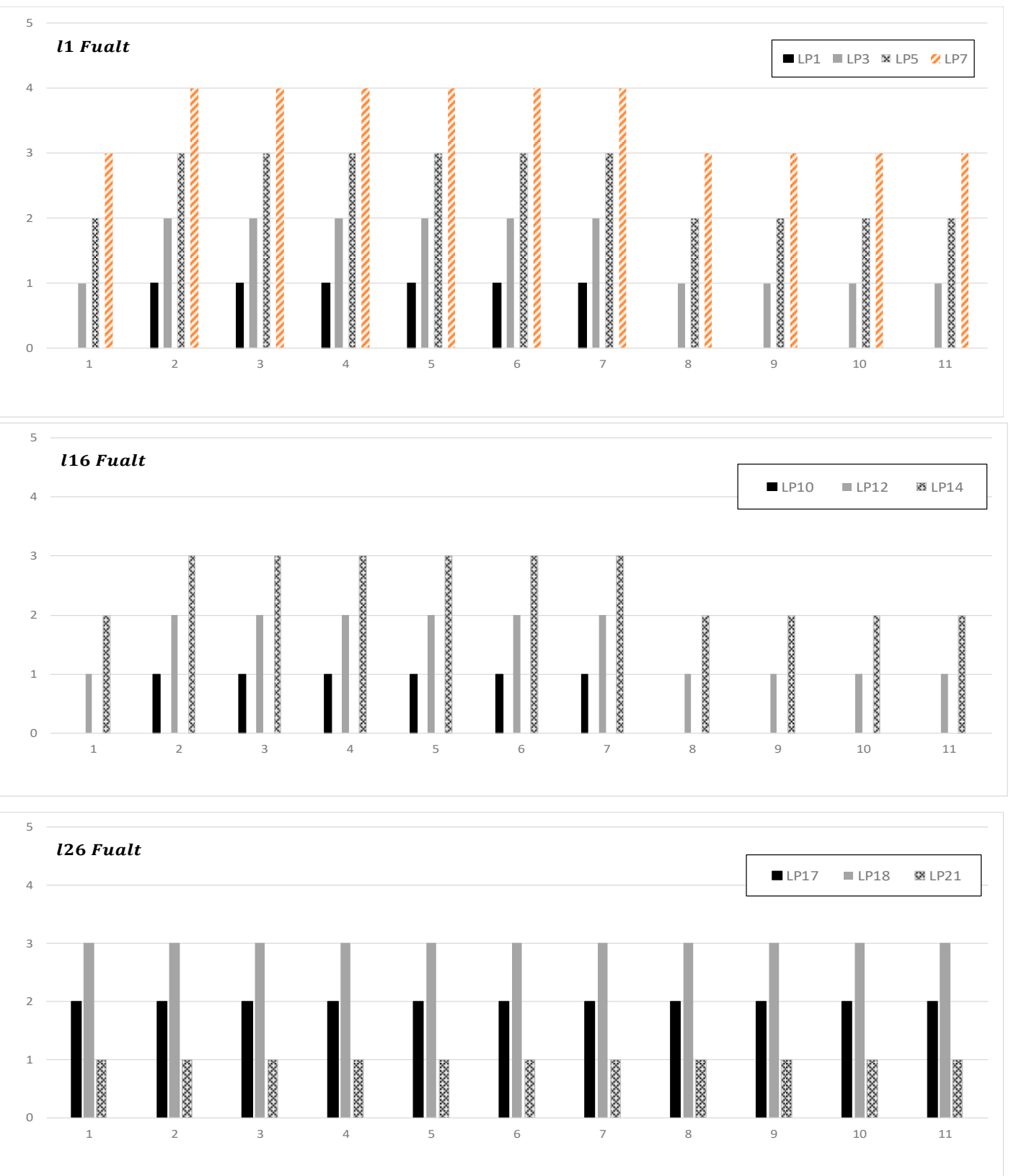

Figure 9. Load priority according to the fault section and fault time.

In this article, the cases listed below were set for case study:

1. Reliability analysis using the existing RBTS 2 Bus simulation system;

2. Analysis of system reliability with the power supply in the islanded area utilizing EVs in RBTS Bus.

Since the study was on situations where faults occur, improvement of SAIFI was not considered and this was the same for all cases. Proposed methods were applied to calculate the reliability in both cases.

For each fault scenario, the EV optimal connection point for each fault time is as shown in Figure 9. The position of priority 1 over time is the EV optimal connection point, and as shown by each figure, the priority is different over time. Figure 9 shows that the priority of all loads is not shown, which is excluded from the priority calculation because the EV connection does not recover the failure, as the hourly power demand is greater than the power supply through the EV. 
The reliability results for both cases are compared in Table 3, and the degree of reliability enhancement in the cases is indicated in parentheses. ECOST and ENS indices are improved when utilizing an EV in the system. In $l 1$ failure, the ENS and ECOST values in Case 1 were calculated to be 18.98[MWh/yr] and 1,154,100[USD/yr], respectively, and the ENS and ECOST in Case 2 were $12.73[\mathrm{MWh} / \mathrm{yr}$ ] and 1,130,450[USD/yr], respectively, which shows $32.93 \%$ and $2.08 \%$ improvement for Case 1, respectively. In $l 1$ failure, it can be seen that ENS improvement is high, indicating that residential and commercial loads are concentrated in relation to $l 1$ fault.

Table 3. Reliability results for the evaluated cases.

\begin{tabular}{|c|c|c|}
\hline \multirow{2}{*}{ Fault Section } & ENS[MWh/yr] & ECOST[USD/yr] \\
\hline & Case 1 & Case 1 \\
\hline$l 1$ & $18.98 / 12.73(-32.93 \%)$ & $1,154,100 / 1,130,450(-2.08 \%)$ \\
\hline$l 16$ & $29.69 / 24.73(-16.71 \%)$ & $2,886,360 / 2,761,840(-4.36 \%)$ \\
\hline 126 & $49.25 / 44.29(-10.07 \%)$ & $5,430,280 / 5,317,630(-2.08 \%)$ \\
\hline
\end{tabular}

In $l 16$ failure, the ENS and ECOST values in Case 1 were calculated to be $29.69[\mathrm{MWh} / \mathrm{yr}$ ] and 2,886,360[USD/yr], respectively, and the ENS and ECOST in Case 2 were 24.73[MWh/yr] and $2,761,840$ [USD/yr], respectively, which shows $16.71 \%$ and $4.36 \%$ improvement for Case 1 , respectively.

Likewise, In 126 failure, the ENS and ECOST values in Case 1 were calculated to be $49.25[\mathrm{MWh} / \mathrm{yr}$ ] and 5,430,280[USD/yr], respectively, and the ENS and ECOST in Case 2 were 44.29[MWh/yr] and 5,317,630[USD/yr], respectively, which shows $10.09 \%$ and $2.08 \%$ improvement for Case 1, respectively.

Here, the reason for the improvement of ECOST is somewhat lower than that of ENS because it is very difficult to supply power through the EV due to the presence of industrial load.

\section{Conclusions}

This paper proposes a V2G operation strategy when system failure occurs by using EVs with the same concept. By analyzing load types and patterns, within the network, this paper provides a methodology for modeling load priority selection so that a fault can be effectively recovered. Through TSN modeling, the available capacity to supply power at the failure point was calculated, and the optimal V2G location is provided considering hourly load priority. Considering the characteristics of the mobile EV, it responds flexibly to various fault scenarios and improves the reliability of the distribution network through V2G scheduling. Further, the method proposed in this paper was verified through the RBTS Bus 2 test system. EV and V2G operation strategies proposed in this paper increased the distribution network reliability improvements by approximately $16.51 \%$ in ENS, and 2.79\% in ECOST. However, this paper applied some assumptions about uncertainty for the case study and these should be addressed. For instance, consider the various factors such as supply potential of EV users, traffic restrictions and initial SOC degree. Through analysis of traffic volume and road conditions, EV arrival time can be modeled more accurately. Moreover, uncertainties about the initial SOC of the EV supply potential can be considered probabilistically by applying various distribution functions.

This paper is focused on improving the reliability of the distribution network, but it can be applied to various fields. Through TSN modeling as described in this paper, it can be applied in microgrid environments or more complex systems and be utilized as power balance or peak reduction. However, V2G infrastructure should be constructed and a sufficient compensation system for EV users should be prepared.

Due to the global trend of strengthening the regulations on $\mathrm{CO}_{2}$ emissions, the supply of microgrids and EVs is continuously increasing in many countries including Korea. Further, ways of improving power system reliability against natural disasters such as the recent forest fire in Gangwon and earthquakes are being examined. It can be expected that when EV is sufficiently supplied, the results 
of this article would be used to improve the reliability in cases of failure, from the viewpoint of system operation.

Author Contributions: Conceptualization, Methodology and validation, H.-J.L. and B.-C.O.; software, formal analysis and writing-original draft preparation, H.-J.L., B.-C.O. and S.-W.K.; resources, visualization and data curation, B.-C.O. and S.-W.K.; writing-review and editing, H.-J.L., B.-C.O. and S.-Y.K.; Supervision, project administration and funding acquisition, S.-Y.K.; All authors have read and agreed to the published version of the manuscript.

Funding: This research was supported by the KEPCO under the project entitled by "Practical Demonstration of P2G Based on Multi-Microgrid for Grid Connected Operations(R19DA04).

Conflicts of Interest: The authors declare no conflict of interest.

\section{Nomenclature}

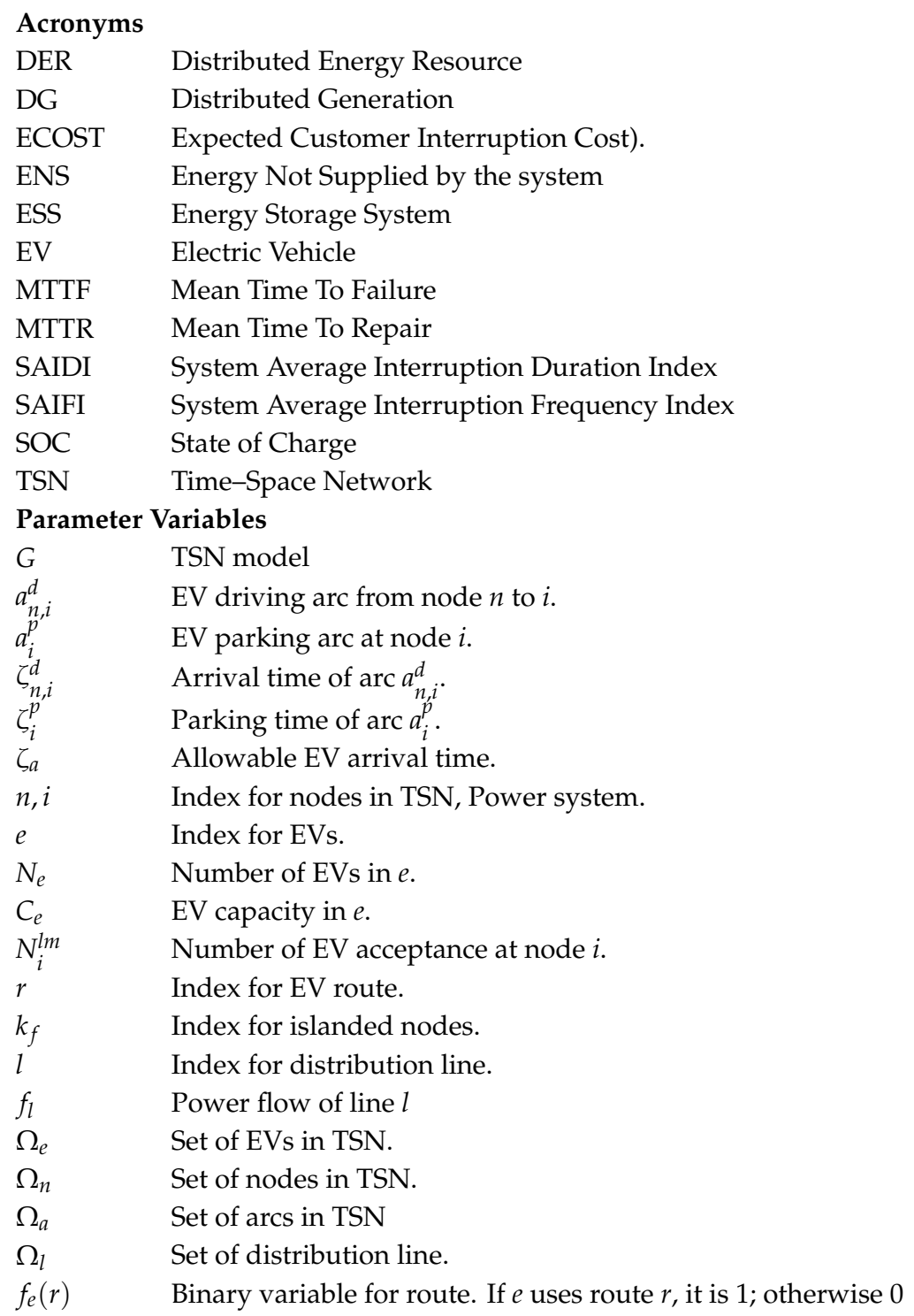

\section{References}

1. Billinton, B.; Billinton, J. Distribution system reliability indices. IEEE Trans. Power Deliv. 1989, 4, 561-568. [CrossRef]

2. Allan, R.; Billinton, R. Probabilistic assessment of power systems. Proc. IEEE 2000, 88, 140-162. [CrossRef] 
3. Billinton, R.; Allan, R.N.; Salvaderi, L. Applied Reliability Assessment in Electric Power Systems; IEEE: Piscataway Township, NJ, USA, 1991.

4. Hou, K.; Jia, H.; Xu, X.; Liu, Z.; Jiang, Y. A continuous time Markov chain based sequential analytical approach for composite power system reliability assessment. IEEE Trans. Power Syst. 2015, 31, 1-11.

5. Conti, S.; Rizzo, S.A. Monte Carlo Simulation by Using a Systematic Approach to Assess Distribution System Reliability Considering Intentional Islanding. IEEE Trans. Power Deliv. 2014, 30, 64-73. [CrossRef]

6. Lin, Y.; Li, Y.; Zio, E. A reliability assessment framework for systems with degradation dependency by combining binary decision diagrams and Monte Carlo simulation. IEEE Trans. Syst. Man, Cybern. Syst. 2015, 46, 1556-1564. [CrossRef]

7. Na, M.-S.; Kim, J.-O. Reliability Evaluation of Micro-grids Containing PV System and Hydropower Plant. Energies 2019, 12, 343. [CrossRef]

8. Brown, R.E.; Gupta, S.; Christie, R.D.; Venkata, S.S.; Fletcher, R. Distribution system reliability assessment using hierarchical Markov modeling. IEEE Trans. Power Deliv. 1996, 11, 1929-1934. [CrossRef]

9. Carmen, L.T.; Borges, D.; Falcão, M. Optimal distributed generation allocation for reliability, losses, and voltage improvement. Int. J. Electr. Power Energy Syst. 2006, 28, 413-420.

10. Wang, H.; Zhang, X.; Li, Q.; Wang, G.; Jiang, H.; Peng, J. Recursive method for distribution system reliability evaluation. Energies 2018, 11, 2681. [CrossRef]

11. Escalera, A.; Castronuovo, E.D.; Prodanović, M.; Roldán-Pérez, J. Reliability assessment of distribution networks with optimal coordination of distributed generation, energy storage and demand management. Energies 2019, 12, 3202. [CrossRef]

12. Sayed, A.; El-Shimy, M.; El-Metwally, M.; Elshahed, M. Reliability, Availability and Maintainability Analysis for Grid-Connected Solar Photovoltaic Systems. Energies 2019, 12, 1213. [CrossRef]

13. Brown, R.E.; Pinkerton, R. Distribution Reliability Optimization Using Synthetic Feeders. Energies 2019, 12, 3510. [CrossRef]

14. Su, S.; Hu, Y.; He, L.; Yamashita, K.; Wang, S. An Assessment Procedure of Distribution Network Reliability Considering Photovoltaic Power Integration. IEEE Access 2019, 7, 60171-60185. [CrossRef]

15. Liu, W.; Guo, D.; Xu, Y.; Cheng, R.; Wang, Z.; Li, Y. Reliability Assessment of Power Systems with Photovoltaic Power Stations Based on Intelligent State Space Reduction and Pseudo-Sequential Monte Carlo Simulation. Energies 2018, 11, 1431. [CrossRef]

16. Chen, C.; Wu, W.; Zhang, B.; Singh, C. An Analytical Adequacy Evaluation Method for Distribution Networks Considering Protection Strategies and Distributed Generators. IEEE Trans. Power Deliv. 2014, 30, 1392-1400. [CrossRef]

17. Ndawula, M.B.; Djokic, S.Z.; Hernando-Gil, I. Reliability Enhancement in Power Networks under Uncertainty from Distributed Energy Resources. Energies 2019, 12, 531. [CrossRef]

18. Mohamad, F.; Teh, J.; Lai, C.-M.; Chen, L.-R. Development of Energy Storage Systems for Power Network Reliability: A Review. Energies 2018, 11, 2278. [CrossRef]

19. Awad, A.S.A.; El-Fouly, T.; Salama, M.M.A. Optimal ESS Allocation and Load Shedding for Improving Distribution System Reliability. IEEE Trans. Smart Grid 2014, 5, 2339-2349. [CrossRef]

20. Kim, S.; Bae, I.; Kim, J. An optimal location for superconducting fault current limiter considering distribution reliability. In Proceedings of the IEEE PES General Meeting, Providence, RI, USA, 25-29 July 2010; pp. 1-5.

21. Neofytou, N.; Blazakis, K.; Katsigiannis, Y.; Stavrakakis, G. Modeling Vehicles to Grid as a Source of Distributed Frequency Regulation in Isolated Grids with Significant RES Penetration. Energies 2019, 12, 720. [CrossRef]

22. Xu, N.Z.; Chung, C.Y. Reliability Evaluation of Distribution Systems Including Vehicle-to-Home and Vehicle-to-Grid. IEEE Trans. Power Syst. 2016, 31, 758-759. [CrossRef]

23. Kavousi-Fard, A.; Rostami, M.A.; Niknam, T. Reliability-Oriented Reconfiguration of Vehicle-to-Grid Networks. IEEE Trans. Ind. Inform. 2015, 11, 682-691. [CrossRef]

24. Yao, S.; Wang, P.; Zhao, T. Transportable Energy Storage for More Resilient Distribution Systems with Multiple Microgrids. IEEE Trans. Smart Grid. 2019, 10, 3331-3341. [CrossRef]

25. Choi, B.-G.; Oh, B.-C.; Choi, S.; Kim, S.-Y. Selecting Locations of Electric Vehicle Charging Stations Based on the Traffic Load Eliminating Method. Energies 2020, 13, 1650. [CrossRef]

26. Oh, B.-G.; Kim, S.-Y. A Study on the Improvement of Distribution System Reliability using V2G Technology. Trans. Korean Inst. Electr. Eng. 2020, 69, 644-649. [CrossRef] 
27. Lopes, J.P.; Moreira, C.; Madureira, A. Defining Control Strategies for MicroGrids Islanded Operation. IEEE Trans. Power Syst. 2006, 21, 916-924. [CrossRef]

28. Ochoa, L.F.; Harrison, G.P. Minimizing Energy Losses: Optimal Accommodation and Smart Operation of Renewable Distributed Generation. IEEE Trans. Power Syst. 2011, 26, 198-205. [CrossRef]

29. Li, F. Distributed Processing of Reliability Index Assessment and Reliability-Based Network Reconfiguration in Power Distribution Systems. IEEE Trans. Power Syst. 2005, 20, 230-238. [CrossRef]

30. Billinton, R.; Allan, R.N. Reliability Evaluation of Power Systems, 2nd ed.; Plenum Publishing Corp: New York, NY, USA, 1996.

31. Kliewer, N.; Mellouli, T.; Suhl, L. A time-space network based exact optimization model for multi-depot bus scheduling. Eur. J. Oper. Res. 2006, 175, 1616-1627. [CrossRef]

32. Osório, G.J.; Shafie-khah, M.; Coimbra, P.D.L.; Lotfi, M.; Catalão, J.P.S. Distribution System Operation with Electric Vehicle Charging Schedules and Renewable Energy Resources. Energies 2018, 11, 3117. [CrossRef]

33. Allan, R.; Billinton, R.; Sjarief, I.; Goel, L.; So, K. A reliability test system for educational purposes-basic distribution system data and results. IEEE Trans. Power Syst. 1991, 6, 813-820. [CrossRef]

34. Son, C.-N.; Han, W.-D.; Moon, J.-F. A Study on the Priority Decision for Interconnection of PV System on Power Distribution System considering Customer Interruption Costs. Trans. Korean Inst. Electr. Eng. 2014, 63, 163-168. [CrossRef]

(C) 2020 by the authors. Licensee MDPI, Basel, Switzerland. This article is an open access article distributed under the terms and conditions of the Creative Commons Attribution (CC BY) license (http://creativecommons.org/licenses/by/4.0/). 